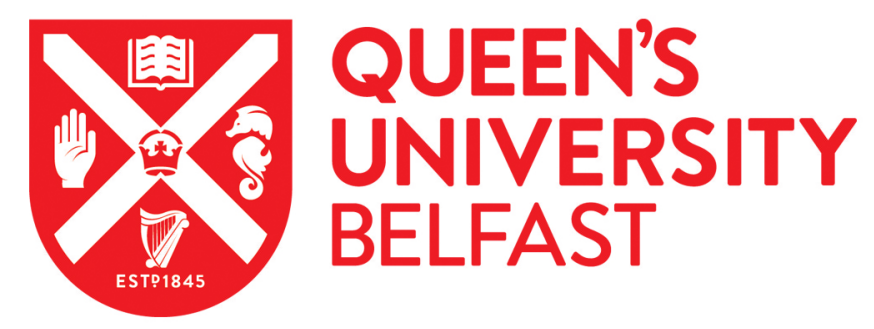

\title{
The chains of the heterodimeric amphibian skin antimicrobial peptide, distinctin, are encoded by separate messenger RNAs
}

Evaristo, G., Pinkse, M., Wang, L., Zhou, M., Wu, Y., Wang, H., Chen, T., Shaw, C., \& Verhaert, P. (2013). The chains of the heterodimeric amphibian skin antimicrobial peptide, distinctin, are encoded by separate messenger RNAs. Journal of proteomics, 78, 245-253. https://doi.org/10.1016/j.jprot.2012.09.016

Published in:

Journal of proteomics

Document Version:

Peer reviewed version

Queen's University Belfast - Research Portal:

Link to publication record in Queen's University Belfast Research Portal

Publisher rights

This is the author's version of a work that was accepted for publication in Journal of Proteomics. Changes resulting from the publishing process, such as peer review, editing, corrections, structural formatting, and other quality control mechanisms may not be reflected in this document. Changes may have been made to this work since it was submitted for publication. A definitive version was subsequently published in Journal of Proteomics, Vol. 78, 14/01/2013

\section{General rights}

Copyright for the publications made accessible via the Queen's University Belfast Research Portal is retained by the author(s) and / or other copyright owners and it is a condition of accessing these publications that users recognise and abide by the legal requirements associated with these rights.

Take down policy

The Research Portal is Queen's institutional repository that provides access to Queen's research output. Every effort has been made to ensure that content in the Research Portal does not infringe any person's rights, or applicable UK laws. If you discover content in the Research Portal that you believe breaches copyright or violates any law, please contact openaccess@qub.ac.uk. 


\section{Accepted Manuscript}

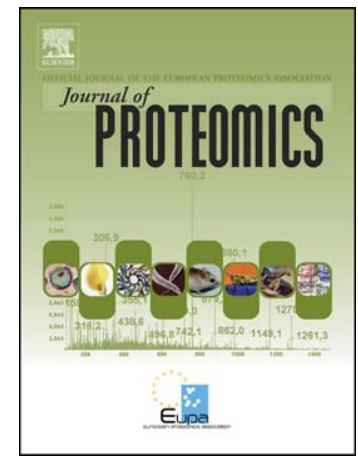

The chains of the heterodimeric amphibian skin antimicrobial peptide, distinctin, are encoded by separate messenger RNAs

Geisa Evaristo, Martijn Pinkse, Lei Wang, Mei Zhou, Youjia Wu, Hui Wang, Tianbao Chen, Chris Shaw, Peter Verhaert

PII:

S1874-3919(12)00660-4

DOI: $\quad$ doi: $10.1016 /$ j.jprot.2012.09.016

Reference: $\quad$ JPROT 1166

To appear in: $\quad$ Journal of Proteomics

Received date: 11 July 2012

Accepted date: $\quad 14$ September 2012

Please cite this article as: Evaristo Geisa, Pinkse Martijn, Wang Lei, Zhou Mei, Wu Youjia, Wang Hui, Chen Tianbao, Shaw Chris, Verhaert Peter, The chains of the heterodimeric amphibian skin antimicrobial peptide, distinctin, are encoded by separate messenger RNAs, Journal of Proteomics (2012), doi: 10.1016/j.jprot.2012.09.016

This is a PDF file of an unedited manuscript that has been accepted for publication. As a service to our customers we are providing this early version of the manuscript. The manuscript will undergo copyediting, typesetting, and review of the resulting proof before it is published in its final form. Please note that during the production process errors may be discovered which could affect the content, and all legal disclaimers that apply to the journal pertain. 


\section{The chains of the heterodimeric amphibian skin antimicrobial peptide, distinctin, are encoded by separate messenger RNAs}

Geisa Evaristo $^{\mathrm{a}}$, Martijn Pinkse ${ }^{\mathrm{a}}$, Lei Wang ${ }^{\mathrm{b}}$, Mei Zhou ${ }^{\mathrm{b}}$, Youjia Wu ${ }^{\mathrm{b}}$, Hui Wang ${ }^{\mathrm{b}}$, Tianbao Chen $^{\mathrm{b}}$, Chris Shaw ${ }^{\mathrm{b}}$ and Peter Verhaert ${ }^{\mathrm{a}, \mathrm{c},}{ }^{*}$.

${ }^{a}$ Analytical Biotechnology Group and Netherlands Proteomics Centre, Department of Biotechnology, Delft University of Technology, Delft, The Netherlands.

bLaboratory of Natural Drug Discovery, School of Pharmacy, Queen's University of Belfast, Belfast, United Kingdom.

${ }^{\mathrm{c}}$ Biomedical Research Center, Hasselt University, Diepenbeek, Belgium.

\section{Correspondence:}

*To whom correspondence should be addressed at the Department of Biotechnology, Delft University of Technology, Julianalaan 67, 2628 BC, Delft, The Netherlands. Tel: +31 (15) 278 2332; Fax: +31 (15) 213 3142; e-mail: p.d.e.m.verhaert@ tudelft.nl

\section{Suggested Reviewers:}

1) Prof. Dr. Günter Allmaier, Institute of Chemical Technologies and Analytics, Vienna University of Technology. Getreidemarkt 9/164-IAC, A-1060 Vienna, Austria. Tel: +43 (1) 58801 15160/ Fax: +43 (1) 58801 15199; e-mail: guenter.allmaier@tuwien.ac.at; Member of the Editorial Board of the Journal of Proteomics.

2) Prof. Dr. Per Andrén, Department of Pharmaceutical Biosciences, Medical Mass Spectrometry, University of Uppsala. Husargatan 3, P.O. Box 583, 75123 Uppsala, Sweden. Tel: +46 18471 7206/ mobile: +46 70 1679334/ Fax: +46 18471 2000; email: per.andren@farmbio.uu.se; Member of the Editorial Board of the Journal of Proteomics.

3) Prof. Juan Pablo Albar Ramirez, Department of Structure of Macromolecules, Proteomics Unit, National Center for Biotechnology (CSIC). UAM Campus Cantoblanco, Darwin 3, 28049, Madrid, Spain. Tel. (+34) 91585 4696/ Fax (+34) 91 
585 4613; e-mail: jpalbar@cnb.csic.es; Member of the Editorial Board of the Journal of Proteomics.

\begin{abstract}
Using a primer to a conserved nucleotide sequence of previously-cloned skin peptides of Phyllomedusa species, two distinct cDNAs were "shotgun" cloned from a skin secretionderived cDNA library of the frog, Phyllomedusa burmeisteri. The two ORFs separately encode chains $\mathrm{A}$ and $\mathrm{B}$ of an analog of the previously-reported heterodimeric peptide, distinctin. LC-MS/MS analysis of native versus dithiotreitol reduced crude venom, confirmed the predicted primary sequences as well as the cystine link between the two monomers. Distinctin predominantly exists in the venom as a heterodimer (A-B), neither of the constituent peptides were detected as monomer, whereas of the two possible homodimers (A$\mathrm{A}$ or $\mathrm{B}-\mathrm{B})$, only $\mathrm{B}-\mathrm{B}$ was detected in comparatively low quantity. In vitro dimerization of synthetic replicates of the monomers demonstrated that besides heterodimer, both homodimers are also formed in considerable amounts. Distinctin is the first example of an amphibian skin dimeric peptide that is formed by covalent linkage of two chains that are the products of different mRNAs. How this phenomenon occurs in vivo, to exclude significant homodimer formation, is unclear at present but a "favored steric state" type of interaction between chains is most likely.
\end{abstract}

Keywords: Amphibian skin peptides; cDNA cloning; distinctin; intramolecular disulfide bonds; peptidomics.

\title{
1. Introduction
}

Amphibians are known to release bioactive compounds from their skin granular glands that include alkaloids, steroids, biogenic amines, proteins and peptides [1, 2]. Many hundreds of different peptides, differing in size, charge, hydrophobicity, conformation, primary structure, as well as in post-translational modifications, have been demonstrated in frog defensive skin secretions.

As already reported by Vittorio Erspamer, one of the original frog skin peptide researchers, frogs from the genus Phyllomedusa have skins that are "a treasure trove of biologically-active peptides" [3], due to the large quantities and structural diversity of the peptides that he found 
in members of this taxon. Several Phyllomedusa skin peptides bear striking identities to mammalian (neuro)peptides [3, 4], and exhibit bioactivities in mammalian systems that are consistent with interaction with and activation of endogenous receptors. Other peptide classes include highly-potent antivirals and antimicrobials that are effective against bacteria as well as protozoa (recently reviewed [5, 6]). These rich sources of bioactive peptides are of particular interest to pharmacologists who are continuously searching for potential novel drug leads from unusual sources. Peptides thus far isolated from phyllomedusine skin, belong to diverse families, among which the dermaseptins and phylloseptins represent the largest both in terms of the numbers of peptide sequences identified and in the numbers of species in which they have been found [6]. The emergence of high throughput techniques such as tandem mass spectrometry based "peptidomics" and cDNA cloning have substantially assisted in enlarging the collection of sequences of bioactive (frog skin) peptides. Performance of high resolution mass spectrometry linked to efficient and robust (nano)HPLC or UPLC, is a very powerful combination strategy to collect (partial) amino acid sequence information straight from complex peptide mixtures. The data thus generated can then be validated and/or completed as soon as the nucleic acid sequences of the corresponding mRNAs become available. The latter has been facilitated by use of an efficient molecular cloning approach, developed by Chen and coworkers [7], based on the use of magnetic oligo(dT) beads to extract polyadenylated mRNA sequences directly from only a few milligrams of the actual frog skin secretion. This technique does not require dissected tissue(s) for mRNA extraction, and hence does not necessitate sacrificing secreting donor specimens. Indeed, harmless 'gland milking' appears sufficient to collect frog skin secretions rich in both peptides and (their) corresponding messenger RNAs.

One successful strategy to "shotgun" clone novel skin peptide precursor-encoding cDNAs from frog skin cDNA libraries, has proven to be possible by the design of primers from highly-conserved nucleic acid sequences derived from skin peptide precursor-encoding cDNAs from related frog species $[8,9]$.

We here report the cloning and full structural characterization, directly from lyophilized $P$. burmeisteri skin secretion, of two peptide precursor-encoding cDNAs and their encoded peptides which are homologous to chains A and B from the heterodimeric peptide, distinctin, originally isolated from the skin of the related specie, $P$. distincta [10]. Differential analysis of native and reductively-alkylated $P$. burmeisteri distictin demonstrated that the intermolecular disulfide bridge between both chains is an endogenous and specific posttranslational modification (PTM). 
Among the PTMs that are characteristic for amphibian skin peptides, disulfide bonds are not uncommon features. However, most of the cystines in frog peptides are intramolecular. The so-called Rana box, for example, is a conservative C-terminal motif of 5-8 residues between a cystine [11]. This is typical for certain classes of antimicrobial peptides that are active against Gram-positive/-negative bacteria and the yeast, Candida albicans, and is found in peptide groups including the brevinins, gaegurins, nigrocins, odoranains, esculentins, ranalexins, dybowskins, japonicins, palustrins and ranatuerins [12-16]. Other conserved internal disulfide-bridged domains in frog skin peptides are known, such as in the skin calcitonin-gene related peptide and the Kazal protease inhibitor peptides, found in P. bicolor and P. sauvagei, respectively $[17,18]$.

Intermolecular disulfide bonds, however, are quite rare in amphibian skin peptides. The only example so far is distinctin, a $5.4 \mathrm{kDa}$ heterodimer composed of two different peptide chains containing 22 and 25 residues, respectively, that was originally identified in the skin secretion of the phyllomedusine frog, $P$. distincta. It has antimicrobial activity against Gram-negative and Gram-positive bacteria $[10,19,20]$, and the dimerization was found to enhance the peptides' bioactivity with respect to that of each monomer. In this context, heterodimeric peptides may represent a new class of amphibian skin peptide with potent biological/pharmacological activity that relies upon the formation of intermolecular complexes. This has inspired other researchers to actually engineer disulfide bridges into natural monomeric and linear amphibian skin peptides to form such complexes. Bioassays indeed subsequently confirmed that synthetic heterodimers, such as between magainin 2 and PGLa, and between magainin and its analogue pexiganan (i.e., MSI-78), showed a greatly enhanced antimicrobial activity when compared to the original native (monomeric) peptides [21].

\section{Materials and Methods}

\subsection{Skin secretion collection}

About 10 specimens of Phyllomedusa burmeisteri, one of the Brazilian walking leaf frogs, were captured during expeditions (January 2009) in the Pacotuba Forest (Cachoeiro de Itapemirim City), and at a local farm (Brunoro's, at Venda Nova do Imigrante City), both in the State of Espírito Santo (Brazil). Skin secretion samples were collected in the field by gentle transdermal electrical stimulation, essentially as described by Tyler and coworkers 
[22]. The secretions were jet-washed from the sampled frog with deionized water, after which the donors were immediately released back into their natural environment. Skin secretions from several individuals (males and females) were filtered over cellulose acetate $(0.2 \mu \mathrm{m}$ pore size), pooled, frozen, lyophilized, and stored at $-20 \mathrm{C}$ prior to analysis.

The required permit to access the genetic heritage information was obtained from the Brazilian Institute of Environment and Renewable Natural Resources (IBAMA license number 010453/2010-5).

\subsection{Peptide separation and mass spectrometry}

One $\mathrm{mg}$ of lyophilized crude skin secretion was diluted in $25 \mathrm{mM} \mathrm{NH} \mathrm{NCO}_{3}$. This sample was divided in two. One part was reduced ( $2 \mathrm{mM}$ dithiothreitol (DTT)) and alkylated (4 $\mathrm{mM}$ iodoacetamide (IAM)). Equivalents of 200 micrograms of both samples - native and reduced - were separately analyzed by HPLC (Waters 2695 Alliance, Manchester, UK), on a C4 column (Reprosil C4, $5 \mu \mathrm{m}$ particles, $2 \mathrm{~mm}$ x $150 \mathrm{~mm}$, Dr. Maish, Germany) coupled on-line to a tandem mass spectrometer. The column was eluted (solvent A, 0.05\% TFA, 0.1 M HAc; and B, $0.05 \%$ TFA, $0.1 \mathrm{M}$ HAc in acetonitrile) by a linear gradient from 0 to $60 \% \mathrm{~B}$ at $0.75 \%$ $\mathrm{min}^{-1}$, and the eluate was directly nanosprayed into a Q-TOF (QTof Premier, Waters, Manchester, UK). Of the crude secretion, $0.1 \mu \mathrm{g}$ was also analyzed by nanoLC using a C8 capillary column (Reprosil-Pur $120 \mathrm{C} 8,5 \mu \mathrm{m}$ particles, $150 \mathrm{~mm}$, Dr. Maish, Germany) coupled to a linear trap-Orbitrap (Orbitrap Velos, ThermoFisher Scientific, Bremen, Germany).

To facilitate the location of peptides containing cystine, PTM-driven differential peptide displays were generated by MSight (SIB, Geneva, Switzerland) as described earlier [23]. This proved an elegant way to assess the presence of the various distinctin dimers and monomers in both untreated and reduced secretions.

For extensive targeted collision-induced fragmentation analysis of all distinctin ions, the respective peaks were manually selected at their retention times in a separate replicate LC MS/MS run.

\subsection{Molecular cloning of distinctin peptides chains $A$ and $B$}

Five $\mathrm{mg}$ of lyophilized skin secretion were dissolved in $1 \mathrm{ml}$ of cell lysis/mRNA stabilization solution (Dynal, UK). Polyadenylated mRNA was isolated using magnetic oligo-dT beads as 
described by the manufacturer (Dynal Biotech, UK). The isolated mRNA was subjected to 5' and 3'- RACE procedures to obtain full-length peptide precursor nucleic acid sequence data using a SMART-RACE kit (Clontech UK). Briefly, the 3'-RACE reactions employed a nested universal primer (NUP - supplied with the kit) and a degenerate sense primer (N2-S1; 5'ACTTTCYGAWTTRYAAGMCCAAABATG-3'), that was complementary to a conserved sequence 5 ' to the putative signal peptide (including the startcodon ATG). This primer had been successfully used to clone different skin secretion peptides from other Phyllomedusa species $[8,9]$. 3'-RACE reaction products were gel-purified, cloned using a pGEM-T vector system (Promega Corporation) and sequenced using an automated DNA sequencer (ABI 3100).

\subsection{Peptide synthesis and oxidation reactions}

A and B chains were synthesized by standard solid-phase Fmoc chemistry on an automated peptide synthesizer (Protein Technologies PS3, Tucson, AZ, USA).

Molar equivalents of synthetic chains A and B were 'incubated' (one week at RT) with themselves or in combination in two different conditions: i) in $\mathrm{H}_{2} \mathrm{O}$ and ii) in $50 \mathrm{mM}$ $\mathrm{NH}_{4} \mathrm{HCO}_{3} \mathrm{pH} 8.0$, containing 5\% DMSO. In the $\mathrm{H}_{2} \mathrm{O}$ condition the synthetic chains were merely diluted in water individually and A plus B mixed, and analyzed by LC MS/MS. In the other condition the three possible combinations of chains (only A, only B and A plus B) were induced to oxidize in bicarbonate buffer in 5\% DMSO pH 8.0, and measured by MS.

\section{Results}

\section{1. "Shotgun" cloning of distinctin chain precursor-encoding cDNAs}

To amplify the distinctin precursor-encoding mRNA sequences present in a cDNA library constructed from lyophilized P. burmeisteri skin secretion, a degenerate primer pool designed to a conserved nucleotide sequence upstream of the putative signal sequence of previously cloned Phyllomedusa skin peptides, was employed for its interrogation [8, 9]. Two full size preprodistinctin cDNAs were thus "shotgun" cloned yielding two different open reading frames (ORFs) with separate start and stop codons.

The prepropeptide sequences can be predicted on the basis of putative prepropeptide convertase motifs and comparisons with similar peptides reported in the literature [7]. The open-reading frame (ORF) of the cDNA encoding the precursor of chain A, contains 69 
amino acid residues, the first 22 of which, comprise a putative signal peptide, followed by a 25-residue acidic 'spacer' peptide and finally the 22-residue mature distinctin A chain peptide. The ORF of the cDNA encoding the precursor of chain $\mathrm{B}$ contains 67 residues, that includes a 20-residue putative signal peptide, a 22- residue acidic spacer and a 25-residue mature distinctin B chain peptide (Fig. 1).

The mature distinctin A- and B-chain peptide sequences are structurally very similar to those described for the original $P$. distincta peptide [10]. A significant difference in the primary structure is at residue 7 of the A-chain, which is an alanine (A) in the $P$. burmeisteri peptide, whereas the $P$. distincta homolog has a proline $(\mathrm{P})$ in this position.

\subsection{Identification of homo- and heterodimers by $M S$}

MS analysis of crude P. burmeisteri skin secretion confirmed the existence of distinctin predominantly as a heterodimer (Fig. 2). The amino acid sequences of the chains were determined by collision-induced dissociation (CID) of both monomers that had been generated by reduction and alkylation of the venom components. MS/MS analysis was carried out using Q-TOF MS as well as by linear ion trap-Orbitrap tandem mass spectrometry. De novo sequencing of both chains, fully confirmed the sequences predicted from the "shotgun" cloned precursor cDNAs: a 22-residue mature A-chain: ENREVPAGFTALIKTLRKCKII, and a 25-residue mature B-chain, NLVSGLIEARKYLEQLHRKLKNCKV. In the DTTtreated skin secretion, as expected, no dimers remained (neither homo- nor heterodimers), which can easily be seen in the PTM-driven differential peptide display of reduced versus untreated (native) sample (Fig. 3).

The distinctin heterodimer, (A-B, $m / z 779.45(7+$ charge state) $)$, in the zoomed-in area of Fig. 3) was present exclusively in the native sample (complete absence in the DTT-treated venom). On the other hand, the monomeric A-chain $(\mathrm{m} / \mathrm{z}, 625.96)$ and B-chain $(\mathrm{m} / \mathrm{z}, 738.92$, four times charged), were entirely absent from crude native skin secretion indicating that in this, they are cross-linked (by cystine bonds) and that the native heterodimer was efficiently reduced by the DTT treatment.

Likewise, targeted analysis identified the homodimer B-B in the native skin secretion (high resolution FTMS analyses; Fig. 2A). The ion intensity of the heterodimer is clearly higher than homodimer B-B, suggesting heterodimeric distinctin is present in a higher concentration than the homodimer B-B. No monomeric chain A or B, or any of the homodimer A-A, were detected in native skin secretion. 
The heterodimer was observed at $m / z 909.19[\mathrm{M}+6 \mathrm{H}]^{6+}$, or parent mass 5,449.12 Da. This exactly equals the sum of the masses of chains $\mathrm{A}$ and $\mathrm{B}$, minus the mass of 2 protons (disulfide formation from two cysteines). CID of this heterodimer ion precursor indeed yielded both $\mathrm{b}$ - and $\mathrm{y}$-ions (as well as immonium ions) representing the $\mathrm{N}$-terminal sequences of chains A and B (peaks highlighted in Fig. 2B). Sequence ions representing residues close to the cystine connection could not be identified, due to the covalent bond between the chains. Similarly the homodimer B-B, with an observed molecular mass of 5,901.34 Da was selected and CID fragmented, showing only chain B amino terminal sequence ions. The precursor mass as well as the occurrence of charge states higher than 8 (protonatable residues $(\mathrm{R}, \mathrm{K}, \mathrm{H}$, and the amino terminus)) proved that it is indeed the covalent dimer.

\subsection{In vitro oxidation of synthetic replicates of distinctin $A$ - and $B$ - chains}

In an attempt to answer the intriguing questions as to how/why two peptide chains originating from two different ORFs preferentially form heterodimers, synthetic replicates of the peptide monomers were made and their in vitro dimerizations were studied by high resolution nano LC MS/MS.

Synthetic A- and B-chains were either left to react in $\mathrm{H}_{2} \mathrm{O}$ or in bicarbonate buffer containing $5 \%$ DMSO. In $\mathrm{H}_{2} \mathrm{O}$, no dimer was formed (Fig. 4A-C). However, air oxidation of the chains in bicarbonate buffer containing 5\% DMSO, induced partial dimerization. Chain A appeared nearly $100 \%$ oxidized when left to react with itself (Fig. 4D), whereas the oxidation to form homodimer B-B, was incomplete (Fig. 4E). The oxidation reaction containing both chains, resulted in the formation of all possible dimers: heterodimer A-B, homodimer B-B and a little homodimer A-A. Only traces of chain A and B monomer remained (Fig. 4F). These oxidation reactions showed no clear preferential dimer formation. They also demonstrated that, in the absence of the other chain, both homodimers can be formed.

To reiterate, the native frog skin secretion contained significantly more heterodimer A-B than homodimer B-B, whereas homodimer A-A was not detected.

\section{Discussion}

Here, we report the molecular cloning of cDNAs encoding the precursor sequences of two chains, $\mathrm{A}$ and $\mathrm{B}$, that constitute the heterodimeric peptide, distinctin, from the skin secretion of Phyllomedusa burmeisteri. The corresponding mature peptide gene products were detected 
in chromatographic fractions of the skin secretion as a distinctin heterodimer using MS. The only heterodimeric peptide described to date in amphibian skin secretions is the peptide, distinctin, from Phyllomedusa distincta, with a fully-established primary structure and antimicrobial activity [10]. The homodimer B-B, was also identified in the skin secretion of P. burmeisteri, and this is the first report of a naturally-occurring distinctin homodimer (Fig. 2A). These data indicate that in vivo, distinctin has a strong tendency to exist as a disulfidebridged dimer. Heterodimerization seems to be preferred, but the detection of the homodimer suggests that rather than to exist as a monomer, excess peptide chains will homodimerize. Interestingly, the cloning and sequencing data indicate that the chains which in vivo are detected as heterodimers, are encoded by two different mRNA-encoded precursors, each with their own start and stop codon, that probably represent two distinct gene products.

Scrutinizing the protein sequence database (UniProt) found that $P$. burmeisteri chain B exhibits a $71 \%$ sequence homology with a distinctin-like peptide chain sequence previously cloned from Phyllomedusa azurea [24]. This sequence does not contain any cysteinyl residues and a chain $\mathrm{A}$ equivalent in this species was not reported. Thus, this species of phyllomedusine frog provides further, albeit indirect evidence, that chain B appears not to be encoded by the same ORF as chain A.

The mechanism behind the specific dimerization of the two P. burmeisteri chains from a pool of peptides containing single free cysteine residues, remains intriguing. Other natural heteroand/or homodimeric peptides from venoms have been cloned and their nucleic acid sequences reported. These include the paralytic heterodimer, pimplin, from the wasp, Pimpla hypochondriaca [25]; the histamine-releasing homodimer, pilosulin 5, from the ant, Myrmecia pilosula [26]; hetero- and homo-dimeric $\alpha \mathrm{D}$-conotoxins (VxXXA, VxXXB and VxXXC) found in the venoms of several marine cone snails of the genus Conus [27]; salmorin, a thrombin-induced fibrinogen-clotting inhibitor from the snake, Agkistrodon halys [28]; numerous dimeric disintegrins, cloned from Vipera and Echis snakes [29-31]; irditoxin, a neurotoxic dimer from the brown treesnake, Boiga irregularis [32]; and various secretory enzymes of the phospholipase A2 family, such as the heterodimers, imperatoxin I and phospholipidin from Pandinus imperator [33, 34] -, and HDP-1P and HDP-2P subunits of the neurotoxic and anti-coagulant heterodimer from Vipera nikolskii [35]. As in the case of the well-known example insulin [36], most of these heterodimers arise from a single mRNA precursor, which is translated in one continuous peptide sequence. This is thought to be a crucial step in the heterodimer formation, which occurs during or immediately after translation. A connecting peptide (of varying length in insulin and the various venom 
heterodimers) between both mature chains is spliced out by specific endoproteases, and this occurs after the disulfide bridge(s) formation.

The cDNAs of disintegrins, salmorin and irditoxin chains represent an exception to this rule, with both monomers encoded by different open reading frames. However, in all these cases, the pre-peptide sequences of A and B chains are very similar or almost identical (typically $>70 \%$ sequence identity), which suggests that a gene duplication lies at the origin of both ORFs. In disintegrins, for example, it is suggested that the A chain precursor gene was derived from a B chain gene duplication. Subsequent deletion of a continuous and large base pair sequence of the ORF, encoding a C-terminal metalloprotease domain in the B chain prepeptide gene and of a $\mathrm{N}$-terminal portion of the disintegrin domain, are thought to produce the final structure of the A chain [30]. Therefore, the disulfide connection between the subunits would proceed similarly as in homodimers (which are also detected in these venoms), where the dimerization takes place by virtue of the simultaneous presence of the chains in the endoplasmic reticulum (ER) during the translation process.

The case of the heterodimeric P. burmeisteri distinctin is markedly different. The peptides representing the signal peptide, acidic spacer and mature peptide of each chain all exhibit different lengths as well as many sequence dissimilarities, yielding an overall sequence identity of only $47 \%$.

This suggests that a different mechanism may be behind the dimerization of these dissimilar subunit chains, perhaps comparable to what happens when antibody molecules (immunoglobulins) are maturing, with heavy and light chains translated from different chromosomes "finding" each other and oxidizing in the ER [37]. This is a hypothesis, and the actual mechanism of in vivo heterodimer formation is still unclear.

In an attempt to obtain information on potential physicochemical constraints in the formation of the possible dimers from the two subunits identified, in vitro dimerization experiments were performed with synthetic replicates of the monomer peptides. However, this did not provide clues as to whether (sequence specific) physiochemical phenomena would preferably direct the formation of one dimer over the other. Our results indicate that both the heterodimer and the two homodimers can be formed in vitro. This is similar to what has been described for magainin and conotoxin synthetic dimers $[38,39]$. It should be mentioned that during in-vitro oxidation experiments cystine formation could be induced by oxygen or trace amounts of metals. In addition, it is also very well possible that the synthetic peptides do not have the proper secondary/tertiary structure to promote chain specific dimerization and/or induce disulfide bond formation. 
Although, in the native $P$. burmeisteri skin secretion the main compound detected was the heterodimer, followed by the homodimer B-B, no homodimer A-A, or A or B monomers, were detected. Why the heterodimer prevails in the P. burmeisteri skin secretion remains an unanswered question, and we can only speculate at this time. Structure modeling and NMR studies on the similar distinctin chains of $P$. distincta has indicated that matching hydrophobic areas on the outer surfaces of chain A and B and alpha-helices, may play a role in bringing both chains together $[19,40-42]$. These studies, however, did not look at the structure of the homodimers.

Comparative proteolytic degradation assays of distinctin and synthetic peptide analogues reported that distinctin is more resistant to serine protease breakdown as a heterodimer than as monomers or homodimers $[19,20]$. The situation in the $P$. burmeisteri skin secretion, with most of the distinctin occurring as a heterodimer, may reflect a similar situation.

Previous investigations have assessed the antimicrobial activity of all possible forms of the closely-related $P$. distincta distinctins $[19,20]$. They found that the heterodimer has broadspectrum antimicrobial activity, and that the dimers (hetero- or homo-) are more active than the separate monomers.

With the $P$. burmeisteri distinctins differing in only a single amino acid residue, the bioactivity is likely to be very similar. This would mean that the relative amounts of distinctin chains in the $P$. burmeisteri skin secretion is consistent with maximization of its bioactivity.

To assess this, we performed pilot bioactivity studies (E. coli growth inhibition test) using dilution series of equivalent amounts of monomeric and in vitro dimerized synthetic peptides (see Fig. 4). Our preliminary data indicate that indeed the $P$. burmeisteri dimers have higher specific bioactivity than the monomers, and that the sample containing the heterodimer exhibits the highest antibiotic effect, confirming what was reported for P. distincta distinctin. With the present emergence of multiple-drug resistant strains of many pathogenic microorganisms and diseases requiring a pharmaceutical solution, the development of novel and potently-active pharmaceutical agents with potential clinical and therapeutic applications could be exemplified by natural molecules like the $P$. burmeisteri distinctin heterodimer reported here. 


\section{Conclusion}

Distinctin, a $5.4 \mathrm{kDa}$ heterodimeric peptide with antimicrobial activity was identified within the skin secretion of Phyllomedusa burmeisteri. Molecular cloning of the cDNA encoding the two chains that constitute this heterodimeric peptide reveals they originate from two different mRNA-encoded precursors, each with their separate start and stop codon. MS analysis showed that in the crude venom the two chains are primarily present as the heterodimer A-B, a subfraction as homodimer B-B, whereas neither homodimer A A nor the individual A of B chains were observed. In vitro oxidation experiments with synthetic chains showed no preferential formation of hetero- of homodimer, suggesting there is an alternative mechanism for dimer formation in-vivo. To our knowledge this is the first example of an amphibian skin dimeric peptide that is formed by covalent linkage of two chains that are the products of different mRNAs.

\section{Acknowledgements}

We are grateful to Prof. Dr. Celio F. B. Haddad for identification of the frogs, and to Mr. Helimar Rabello and his students for guiding and helping with frog capturing.

This study was partly funded by the Netherlands Genomics Initiative (NGI) and the Brazilian National Council of Technological and Scientific Development (CNPq - grant GDE200847/2007-04). 


\section{Figures Legends}

Figure 1: Nucleotide sequences of precursor cDNAs encoding Phyllomedusa burmeisteri distinctin chain A (A) and distinctin chain B (B) cloned from a skin secretion-derived library. Putative signal peptides (double-underlined), mature processed peptides (single-underlined) and stop codons (asterisks) are indicated.

Figure 2: Distinctin dimers in native P. burmeisteri skin secretion. (A) Combined MS spectrum of elution times in nanoLC chromatogram of both distinctin dimers. Spectrum shows presence of heterodimer (green peaks) and homodimer B-B (magenta peaks), among several other (higher and lower abundant) non-distinctin peptide peaks. Both distinctin dimers appear as multiply charged ions $(\mathrm{z}=5$ until $\mathrm{z}=10)$ with heterodimer being most abundant. (B) Tandem MS of heterodimer (precursor ion at m/z 909.190 selected $\left([\mathrm{M}+6 \mathrm{H}]^{6+}\right)$ ) showing b-, $\mathrm{y}-$, and i- (immonium) ions from both chains A and B. Insert shows primary structure of chain $\mathrm{A}$ and $\mathrm{B}$ with all detected $\mathrm{b}$ - and $\mathrm{y}$ - ions indicated.

Figure 3: Zoomed-in area of PTM-driven differential peptide display of native crude $P$. burmeisteri venom (in blue) and DTT-reduced venom (in red): inserts show $[\mathrm{M}+4 \mathrm{H}]^{4+}$ ions of distinctin monomeric chains $\mathrm{A}(\mathrm{A})$ and $\mathrm{B}(\mathrm{B})$ and $[\mathrm{M}+7 \mathrm{H}]^{7+}$ ions of distinctin heterodimer $(\mathrm{AB})$. Note that sum of mass $(\mathrm{A})$ and mass $(\mathrm{B})$ minus mass $(2 \mathrm{H})$ exactly equals mass $(\mathrm{AB})$. Ions common in both samples have blue and red colors superimposed, yielding blackish spots. Red color of monomers A and B indicate that these ions are not observed in native venom, whereas, conversely, blue heterodimer ions reveal that no heterodimer was detected in DTTreduced venom. (Full PTM-driven differential peptide display is provided as Supplementary Fig. 1).

Figure 4: Deconvoluted MS spectra of in vitro dimerization of synthetic distinctin chains A and B. (A-C) "SYNTHETIC CHAIN(S) A/B/A\&B" represent the mixture after one week of incubation of the respective chains in water. (D-F) "SYNTHETIC DIMERS A-A/B-B/A-B" show the oxidation products after one week in bicarbonate buffer $\mathrm{pH}$ 8.0. Masses of respective chains (monomers) and dimers are indicated by arrows.

Supplementary Figure 1: Full PTM-driven differential peptide display of $P$. burmeisteri crude venom. Selected area is zoomed-in in Fig. 3. 


\section{References}

[1] Daly JW. The chemistry of poisons in amphibian skin. Proceedings of the National Academy of Sciences of the United States of America 1995;92:9-13.

[2] Daly JW, Caceres J, Moni RW, Gusovsky F, Moos M, Jr., Seamon KB, et al. Frog secretions and hunting magic in the upper Amazon: identification of a peptide that interacts with an adenosine receptor. Proceedings of the National Academy of Sciences of the United States of America 1992;89:10960-3.

[3] Erspamer V, Melchiorri P, Falconieri Erspamer G, Montecucchi PC, de Castiglione R. Phyllomedusa skin: a huge factory and store-house of a variety of active peptides. Peptides 1985;6 Suppl 3:7-12.

[4] Erspamer V. Amphibian skin peptides in mammals - looking ahead. Trends in Neurosciences 1983;6:200-1.

[5] Leite JR, Silva LP, Rodrigues MI, Prates MV, Brand GD, Lacava BM, et al. Phylloseptins: a novel class of anti-bacterial and anti-protozoan peptides from the Phyllomedusa genus. Peptides 2005;26:565-73.

[6] de Azevedo Calderon L, Silva AdAE, Ciancaglini P, Stabeli RG. Antimicrobial peptides from Phyllomedusa frogs: from biomolecular diversity to potential nanotechnologic medical applications. Amino acids 2011;40:29-49.

[7] Chen T, Zhou M, Chen W, Lorimer J, Rao P, Walker B, et al. Cloning from tissue surrogates: antimicrobial peptide (esculentin) cDNAs from the defensive skin secretions of Chinese ranid frogs. Genomics 2006;87:638-44.

[8] Chen T, Tang L, Shaw C. Identification of three novel Phyllomedusa sauvagei dermaseptins (sVI-sVIII) by cloning from a skin secretion-derived cDNA library. Regulatory peptides 2003;116:139-46.

[9] Chen T, Zhou M, Gagliardo R, Walker B, Shaw C. Elements of the granular gland peptidome and transcriptome persist in air-dried skin of the South American orangelegged leaf frog, Phyllomedusa hypocondrialis. Peptides 2006;27:2129-36.

[10] Batista CV, Scaloni A, Rigden DJ, Silva LR, Rodrigues Romero A, Dukor R, et al. A novel heterodimeric antimicrobial peptide from the tree-frog Phyllomedusa distincta. FEBS letters 2001;494:85-9.

[11] Conlon JM, Kolodziejek J, Nowotny N. Antimicrobial peptides from ranid frogs: taxonomic and phylogenetic markers and a potential source of new therapeutic agents. Biochimica et biophysica acta 2004;1696:1-14.

[12] Chen T, Zhou M, Rao P, Walker B, Shaw C. The Chinese bamboo leaf odorous frog (Rana (Odorrana) versabilis) and North American Rana frogs share the same families of skin antimicrobial peptides. Peptides 2006;27:1738-44.

[13] Park SH, Kim HE, Kim CM, Yun HJ, Choi EC, Lee BJ. Role of proline, cysteine and a disulphide bridge in the structure and activity of the anti-microbial peptide gaegurin 5. The Biochemical journal 2002;368:171-82.

[14] Wang L, Evaristo G, Zhou M, Pinkse M, Wang M, Xu Y, et al. Nigrocin-2 peptides from Chinese Odorrana frogs--integration of UPLC/MS/MS with molecular cloning in amphibian skin peptidome analysis. The FEBS journal 2010;277:1519-31.

[15] Kim SS, Shim MS, Chung J, Lim DY, Lee BJ. Purification and characterization of antimicrobial peptides from the skin secretion of Rana dybowskii. Peptides 2007;28:1532-9.

[16] Conlon JM, Leprince J, Vaudry H, Jiansheng H, Nielsen PF. A family of antimicrobial peptides related to japonicin-2 isolated from the skin of the chaochiao brown frog Rana chaochiaoensis. Comp Biochem Physiol C Toxicol Pharmacol 2006;144:101-5. 
[17] Seon AA, Pierre TN, Redeker V, Lacombe C, Delfour A, Nicolas P, et al. Isolation, structure, synthesis, and activity of a new member of the calcitonin gene-related peptide family from frog skin and molecular cloning of its precursor. The Journal of biological chemistry 2000;275:5934-40.

[18] Gebhard LG, Carrizo FU, Stern AL, Burgardt NI, Faivovich J, Lavilla E, et al. A Kazal prolyl endopeptidase inhibitor isolated from the skin of Phyllomedusa sauvagii. European journal of biochemistry / FEBS 2004;271:2117-26.

[19] Raimondo D, Andreotti G, Saint N, Amodeo P, Renzone G, Sanseverino M, et al. A folding-dependent mechanism of antimicrobial peptide resistance to degradation unveiled by solution structure of distinctin. Proceedings of the National Academy of Sciences of the United States of America 2005;102:6309-14.

[20] Dalla Serra M, Cirioni O, Vitale RM, Renzone G, Coraiola M, Giacometti A, et al. Structural features of distinctin affecting peptide biological and biochemical properties. Biochemistry 2008;47:7888-99.

[21] Gottler LM, Ramamoorthy A. Structure, membrane orientation, mechanism, and function of pexiganan--a highly potent antimicrobial peptide designed from magainin. Biochimica et biophysica acta 2009;1788:1680-6.

[22] Tyler MJ, Stone DJ, Bowie JH. A novel method for the release and collection of dermal, glandular secretions from the skin of frogs. Journal of pharmacological and toxicological methods 1992;28:199-200.

[23] Evaristo G, Pinkse M, Pimenta DC, Chen T, Shaw C, Verhaert P. PTM-driven Differential Peptide Display: Elucidation of Inter / Intra-molecular Disulfide Bridges in Frog Peptides. Ook Press Ltd 2010:579-81.

[24] Thompson AH. A genomic/proteomic approach to isolating and identifying bioactive peptides from the skin secretions of Phyllomedusa hypochondrialis azurea. Uniprot acccession number Q17UZ0 2006;Thesis:University of Ulster Coleraine, United Kingdom.

[25] Parkinson N, Smith I, Audsley N, Edwards JP. Purification of pimplin, a paralytic heterodimeric polypeptide from venom of the parasitoid wasp Pimpla hypochondriaca, and cloning of the cDNA encoding one of the subunits. Insect biochemistry and molecular biology 2002;32:1769-73.

[26] Inagaki H, Akagi M, Imai HT, Taylor RW, Wiese MD, Davies NW, et al. Pilosulin 5, a novel histamine-releasing peptide of the Australian ant, Myrmecia pilosula (Jack Jumper Ant). Archives of biochemistry and biophysics 2008;477:411-6.

[27] Loughnan ML, Nicke A, Lawrence N, Lewis RJ. Novel alpha D-conopeptides and their precursors identified by cDNA cloning define the D-conotoxin superfamily. Biochemistry 2009;48:3717-29.

[28] Koh Y, Chung K, Kim D. Purification and cDNA cloning of salmorin that inhibits fibrinogen clotting. Thrombosis research 2000;99:389-98.

[29] Vija H, Samel M, Siigur E, Aaspollu A, Tonismagi K, Trummal K, et al. VGD and MLD-motifs containing heterodimeric disintegrin viplebedin-2 from Vipera lebetina snake venom. Purification and cDNA cloning. Comparative biochemistry and physiology 2009;153:253-60.

[30] Calvete JJ, Marcinkiewicz C, Monleon D, Esteve V, Celda B, Juarez P, et al. Snake venom disintegrins: evolution of structure and function. Toxicon 2005;45:1063-74.

[31] Calvete JJ, Moreno-Murciano MP, Theakston RD, Kisiel DG, Marcinkiewicz C. Snake venom disintegrins: novel dimeric disintegrins and structural diversification by disulphide bond engineering. The Biochemical journal 2003;372:725-34. 
[32] Pawlak J, Mackessy SP, Sixberry NM, Stura EA, Le Du MH, Menez R, et al. Irditoxin, a novel covalently linked heterodimeric three-finger toxin with high taxonspecific neurotoxicity. Faseb J 2009;23:534-45.

[33] Zamudio FZ, Conde R, Arevalo C, Becerril B, Martin BM, Valdivia HH, et al. The mechanism of inhibition of ryanodine receptor channels by imperatoxin $\mathrm{I}$, a heterodimeric protein from the scorpion Pandinus imperator. The Journal of biological chemistry 1997;272:11886-94.

[34] Conde R, Zamudio FZ, Becerril B, Possani LD. Phospholipin, a novel heterodimeric phospholipase A2 from Pandinus imperator scp6pion venom. FEBS letters 1999;460:447-50.

[35] Ramazanova AS, Zavada LL, Starkov VG, Kovyazina IV, Subbotina TF, Kostyukhina EE, et al. Heterodimeric neurotoxic phospholipases A2--the first proteins from venom of recently established species Vipera nikolskii: implication of venom composition in viper systematics. Toxicon 2008;51:524-37.

[36] Bell GI, Swain WF, Pictet R, Cordell B, Goodman HM, Rutter WJ. Nucleotide sequence of a cDNA clone encoding human preproinsulin. Nature 1979;282:525-7.

[37] Uhr JW. Intracellular events underlying synthesis and secretion of immunoglobulin. Cellular immunology 1970;1:228-44.

[38] Hara T, Mitani Y, Tanaka K, Uematsu N, Takakura A, Tachi T, et al. Heterodimer formation between the antimicrobial peptides magainin 2 and PGLa in lipid bilayers: a cross-linking study. Biochemistry 2001;40:12395-9.

[39] Wu XC, Zhou M, Peng C, Shao XX, Guo ZY, Chi CW. Novel conopeptides in a form of disulfide-crosslinked dimer. Peptides 2010;31:1001-6.

[40] Resende JM, Moraes CM, Munhoz VH, Aisenbrey C, Verly RM, Bertani P, et al. Membrane structure and conformational changes of the antibiotic heterodimeric peptide distinctin by solid-state NMR spectroscopy. Proceedings of the National Academy of Sciences of the United States of America 2009;106:16639-44.

[41] Verardi R, Traaseth NJ, Shi L, Porcelli F, Monfregola L, De Luca S, et al. Probing membrane topology of the antimicrobial peptide distinctin by solid-state NMR spectroscopy in zwitterionic and charged lipid bilayers. Biochimica et biophysica acta 2011;1808:34-40.

[42] Munhoz VHdO, Alcântara AFdC, Piló-Veloso D. Análise Conformacional por Cálculos Teóricos da Distinctina, Peptídeo Antimicrobiano Isolado de Anuros da Espécie Phyllomedusa distincta. Química Nova 2008;31:822-7. 
Figure 1

(A) $\quad \begin{array}{llllllllllllllllll}M & A & F & V & \text { K } & \text { K } & \text { S } & \text { L } & \text { L } & \text { L } & \text { V } & \text { L } & \text { F } & \text { L } & G & \text { L } & \text { V }\end{array}$

1 ATGGCTTTCG TTAAAAAATC TCTTCTCCTT GTACTTTTCC TTGGATTGGT TACCGAAAGC AATTTTTTAG AGAAGAGGAA CATGAAAAGG AACCTAACCA

51 CTCCTTTTCC ATCTGTGAAG GAGGAAAAGG TAGACACTTC TTCTCTTTTC TCTCTGACTT CTCCTGCTCT \begin{tabular}{lllllllllllllllll}
\hline & $E$ & $D$ & $E$ & $I$ & $E$ & $E$ & $E$ & $S$ & $E$ & $E$ & $K$ & $K$ & $R$ & $E$ & $N$ & $R$
\end{tabular}

101 ATGAGGATGA AATAGAGGAA GAAAGTGAAG AGAAGAAAAG AGAGAATCGA TACTCCTACT TTATCTCCTT CTTTCACTTC TCTTCTTTTC TCTCTTAGCT $\begin{array}{llllllllllllllllllllllllll}E & V & P & A & G & F & T & A & L & I & K & T & L & R & K & C & K\end{array}$.

151 GAAGTACCTG CAGGATTCAC TGCATTGATT AAAACATTAA GAAAGTGTAA CTTCATGGAC GTCCTAAGTG ACGTAACTAA TTTTGTAATT CTTTCACATT I I *

201 GATTATATAA TCTAAGTAGT ACAGTTATCA ATGATTATGC CAAAACCATA CTAATATATT AGATTCATCA TGTCAATAGT TACTAATACG GTTTTGGTAT

251 TTAAAGCATA TTTAATGTAA AAAAAAAAAA AAAAAAAAAA AAAAAAAA AATTTCGTAT AAATTACATT TTTTTTTTTT TTTTTTTTTT TTTTTTTT

(B) $\quad \begin{array}{lllllllllllllllllll}M & \text { A } & \text { F } & \text { L } & \text { K } & \text { K } & \text { S } & \text { L } & \text { F } & \text { L } & \text { V } & \text { L } & \text { F } & \text { L } & \text { V } & \text { F } & \text { L }\end{array}$

1 ATGGCTTTCC TTAAAAAATC TCTTTTCCTT GTACTATTCC TTGTATTCCT TACCGAAAGG AATTTTTTAG AGAAAAGGAA CATGATAAGG AACATAAGGA

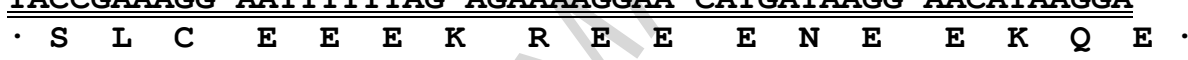

51 TTCTCTCTGT GAAGAAGAGA AAAGAGAAGA GGAAAATGAG GAAAAACAAG AAGAGAGACA CTTCTTCTCT TTTCTCTTCT CCTTTTACTC CTTTTTGTTC

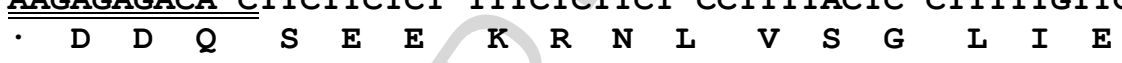

101 AAGACGATCA AAGTGAAGAG AAGAGAAATC TGGTGTCAGG TCTAATAGAA TTCTGCTAGT TTCACTTCTC TTCTCTTTAG ACCACAGTCC AGATTATCTT $\begin{array}{lllllllllllllllll}A & R & K & Y & L & E & Q & L & H & R & K & L & K & N & C & K & V\end{array}$.

151 GCAAGAAAAT ACCTTGAACA GCTGCATCGT AAACTAAAAA ATTGTAAAGT CGTTCTTTTA TGGAACTTGT CGACGTAGCA TTTGATTTTT TAACATTTCA

201 TTAAGAAAAT GTAAAATCTA AGACCTCTAA GAGTGTTTTC ACACGGTGTG ÄATCTTTTA CATTTTAGAT TCTGGAGATT CTCACAAAAG TGTGCCACAC

251 TTTTTGGTGT GTTTTTTGAT GCATTTTTTG TGCAGAGAGG CACAGCAATT AAAAACCACA CAAAAAACTA CGTAAAAAAC ACGTCTCTCC GTGTCGTTAA

301 AATGCTTGCA TTTCTGCACA GGGAAGGCGT CGGAAAACGC ACCAAAAGCA TTACGAACGT AAAGACGTGT CCCTTCCGCA GCCTTTTGCG TGGTTTTCGT

351 CACCTTATGA AACCACCCTA AGGAGCACAA TTACCAATCA TTGTGCCAAA GTGGAATACT TTGGTGGGAT TCCTCGTGTT AATGGTTAGT AACACGGTTT

401 ATAAAATCCA GCATATTTAA ACAAAAAAAA AAAAAAAAAA AAAAAAAAAA TATTTTAGGT CGTATAAATT TGTTTTTTTT TTTTTTTTTT TTTTTTTTTT 
Figure 2
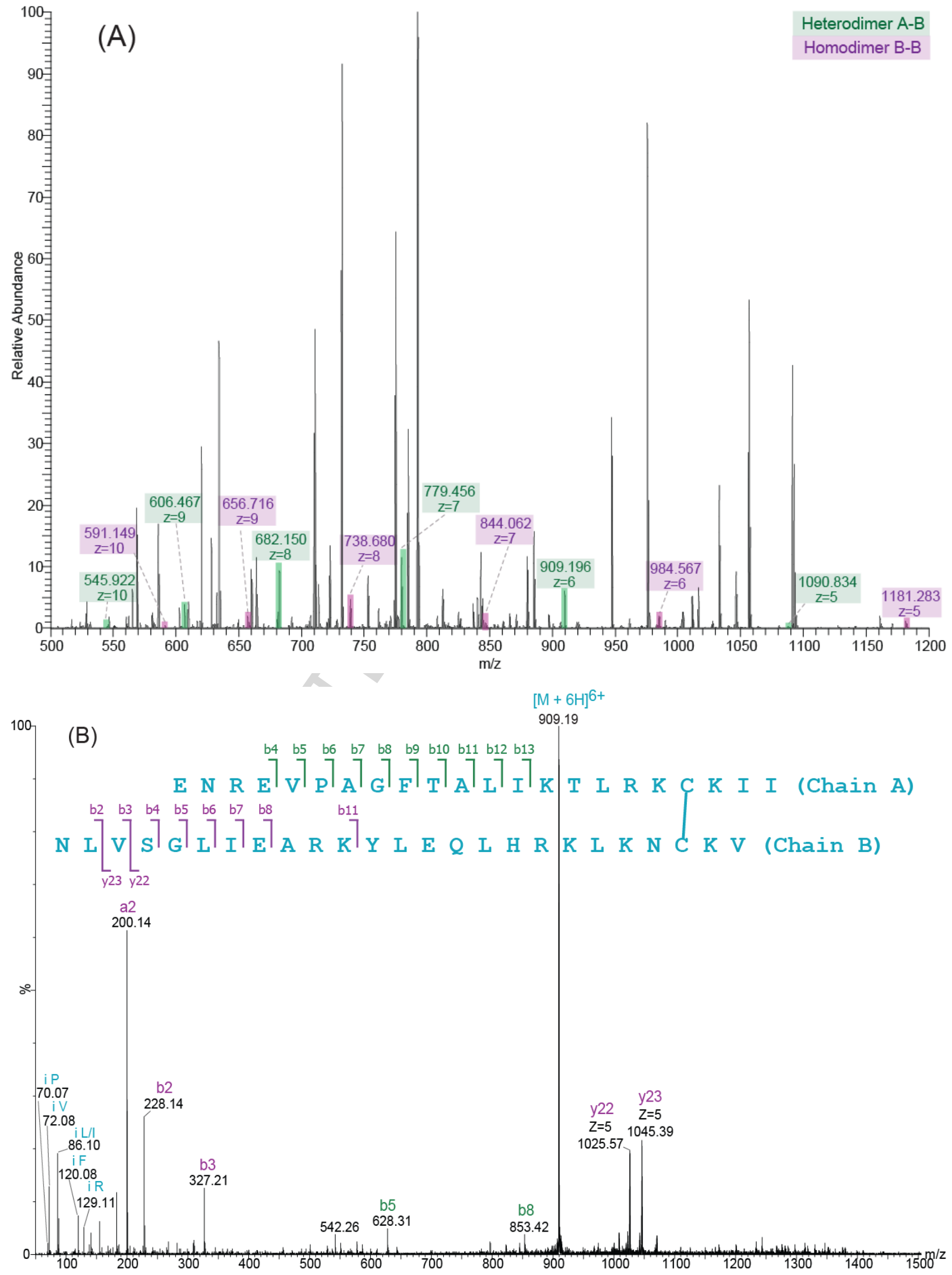
Figure 3

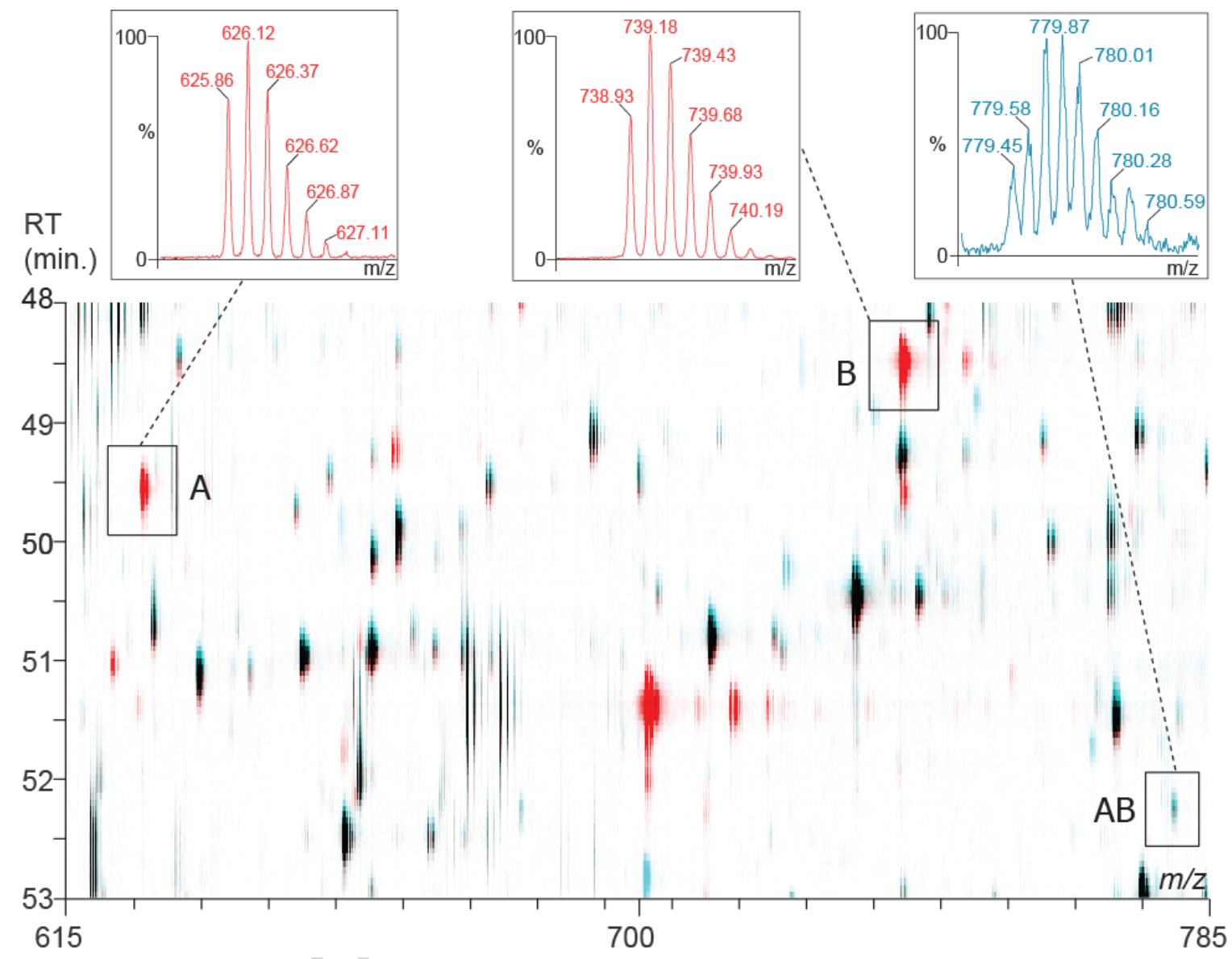


Figure 4

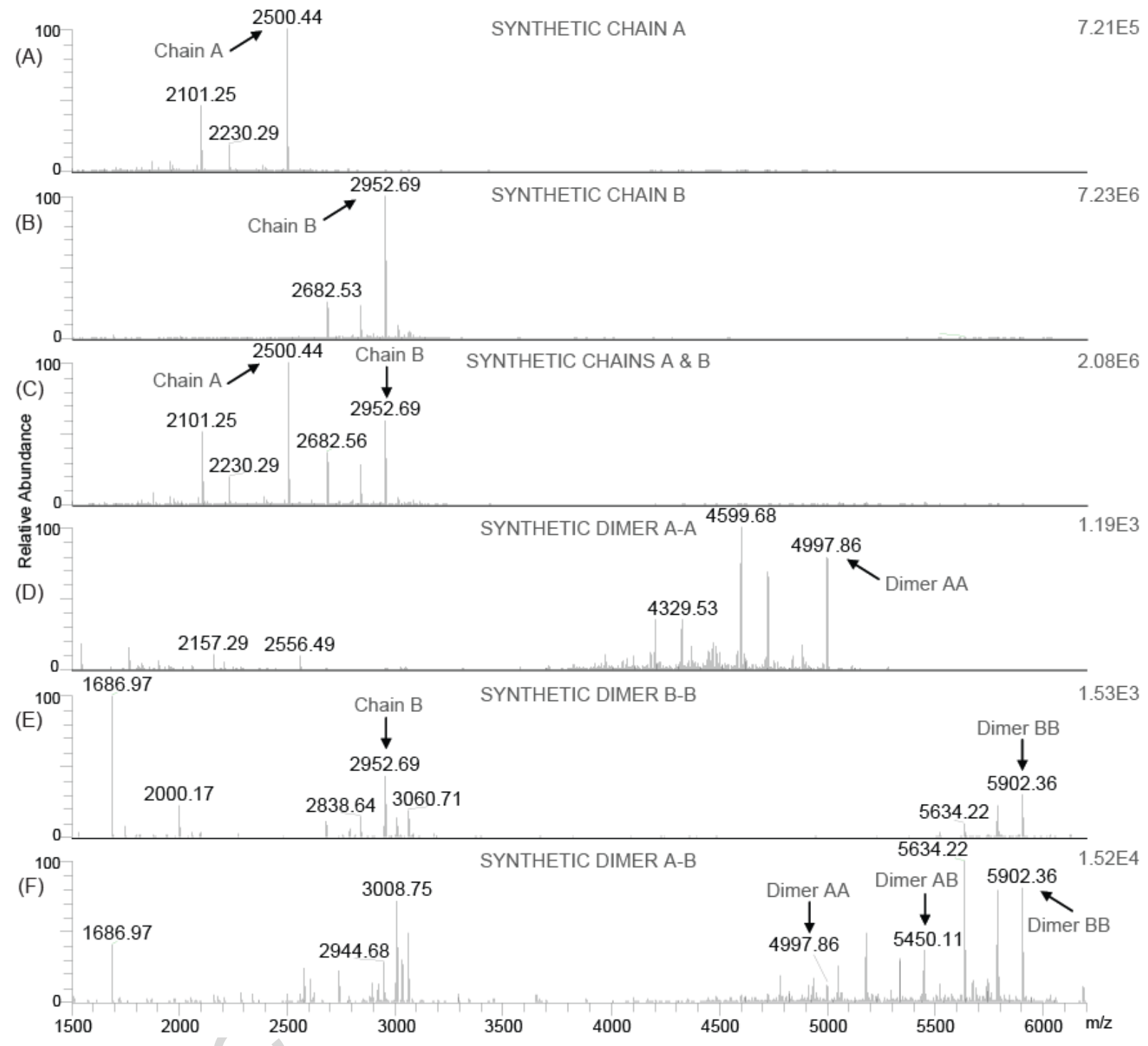


Graphical Abstract

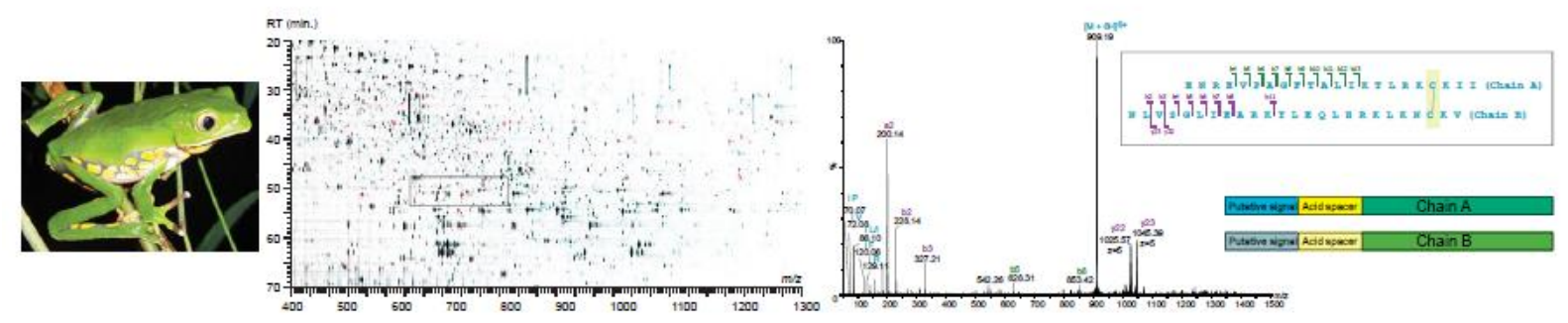


Highlights

1. Peptidome/transcriptome analysis of skin secretion of Phyllomedusa burmeisteri.

2. The two chains of distinctin, a $5.4 \mathrm{kDa}$ dimeric skin peptide, were shotgun cloned.

3. Chains of this heterodimeric peptide are encoded by two different ORFs.

4. In vivo, the hetero-dimeric distinctin is more abundant than homo-dimeric distinctin.

5. In vitro oxidation of synthetic peptides showed no preferential hetero-dimerization. 